\title{
Real-time earthquake detection and hazard assessment by ElarmS across California
}

\author{
Richard M. Allen, ${ }^{1}$ Holly Brown, ${ }^{1}$ Margaret Hellweg, ${ }^{1}$ Oleg Khainovski, ${ }^{1}$ Peter Lombard, ${ }^{1}$ \\ and Douglas Neuhauser ${ }^{1}$
}

Received 25 November 2008; revised 13 January 2009; accepted 15 January 2009; published 5 March 2009.

[1] ElarmS is a network-based methodology for rapid earthquake detection, location and hazard assessment in the form of magnitude estimation and peak ground motion prediction. The methodology is currently being tested as part of the real-time seismic system in California leveraging the resources of the California Integrated Seismic Network (CISN) and the Advanced National Seismic System. A total of 603 velocity and acceleration sensors at 383 sites across the state stream waveform data to ElarmS processing modules at three network processing centers where waveforms are reduced to a few parameters. These parameters are then collected and processed at UC Berkeley to provide a single statewide prediction of future ground shaking that is updated every second. The system successfully detected the $\mathrm{M}_{\mathrm{w}} 5.4$ Alum Rock earthquake in northern California for which it generated an accurate hazard prediction before peak shaking began in San Francisco. It also detected the $\mathrm{M}_{\mathrm{w}} 5.4$ Chino Hills earthquake in southern California. The median system latency is currently $11.8 \mathrm{sec}$; the median waveform data latency is $6.5 \mathrm{sec}$. Citation: Allen, R. M., H. Brown, M. Hellweg, O. Khainovski, P. Lombard, and D. Neuhauser (2009), Real-time earthquake detection and hazard assessment by ElarmS across California, Geophys. Res. Lett., 36, L00B08, doi:10.1029/ 2008GL036766.

\section{ElarmS Philosophy and Methodology}

[2] The process of rapid detection of earthquakes and notification of coming ground shaking has become known as earthquake early warning. Warnings are possible due to the much faster speed of electronic communications relative to those of seismic waves. The available warning time increases with distance from the epicenter. Given the area affected by a single event, the possible warning times range from a few seconds to tens of seconds. These are therefore last-minute warnings. In October 2007 Japan turned on the first publically available national warning system [Hoshiba et al., 2008]. Taiwan, Turkey, Mexico and Romania also have active warning systems [Espinosa Aranda et al., 1995; Hsiao et al., 2009; H. Alcik et al., A study on warning algorithms for Istanbul earthquake early warning system, submitted to Geophysical Research Letters, 2008]. Development is also underway in many other countries (see Gasparini et al. [2007] and other papers in this special section), including the United States. In this manuscript we

\footnotetext{
${ }^{1}$ Seismological Laboratory, University of California, Berkeley, California, USA.
}

Copyright 2009 by the American Geophysical Union. 0094-8276/09/2008GL036766\$05.00 describe the ElarmS methodology currently under testing in California.

[3] ElarmS is a network-based approach to earthquake early warning. The methodology is designed to provide location-specific predictions of peak ground motion and time-til-shaking with the intent of warning users in locations where damaging ground shaking is expected to occur. Data from multiple seismic stations is gathered and integrated to provide real-time detection and assessment of current earthquake activity; each second an updated ground shaking prediction is generated. Telemetry of the data to a central processing site is a requirement of the system. An alternative approach to early warning is the single station method [e.g., Lockman and Allen, 2005; Wu and Kanamori, 2008a, 2008b; Bose et al., 2009] where seismic recordings are translated onsite into warnings. Network-based approaches are slower than a single-station approach, as the warning times are reduced by the time it takes to telemeter the data and warnings, but the integration of data from multiple sites reduces uncertainties and enhances robustness.

[4] To provide information about an earthquake as quickly as possible, ElarmS uses the P-wave recorded on velocity and acceleration sensors to detect, locate and estimate the magnitude of an earthquake. Detailed descriptions of the methodology are given by Wurman et al. [2007] and Tsang et al. [2007]. Here we provide only an outline and focus on the network aspects of the real-time implementation. The standard STA/LTA approach is used to detect seismic arrivals [Allen, 1978] though the sensitivity is lower than for normal monitoring networks as we are only interested in larger $(M>3)$ earthquakes. When a seismic station triggers on a P-wave, ElarmS first tries to associate it with any earthquake currently in progress; otherwise, a new earthquake is declared. The initial location is at the first station to trigger, then between the first two stations based on the arrival times. Once three triggers are available the event is located using a grid search to minimize arrival time residuals. The depth for all events in California is set at $8 \mathrm{~km}$. This simple approach has been found to be effective for two reasons. Firstly, in the San Francisco Bay Area (SFBA) and Los Angeles Metropolitan Area (LAMA) where station coverage is densest in California ( $\sim 20 \mathrm{~km}$ spacing, see Figure 1), two or three stations typically trigger in any onesecond processing interval. By the time the first magnitude estimate is available, one second later, the locations are typically based on 3 or more station trigger times (see the Alum Rock example below). Secondly, our experience shows that 3 to 5 station triggers are preferable before issuing any warning in order to minimize false alarms. 


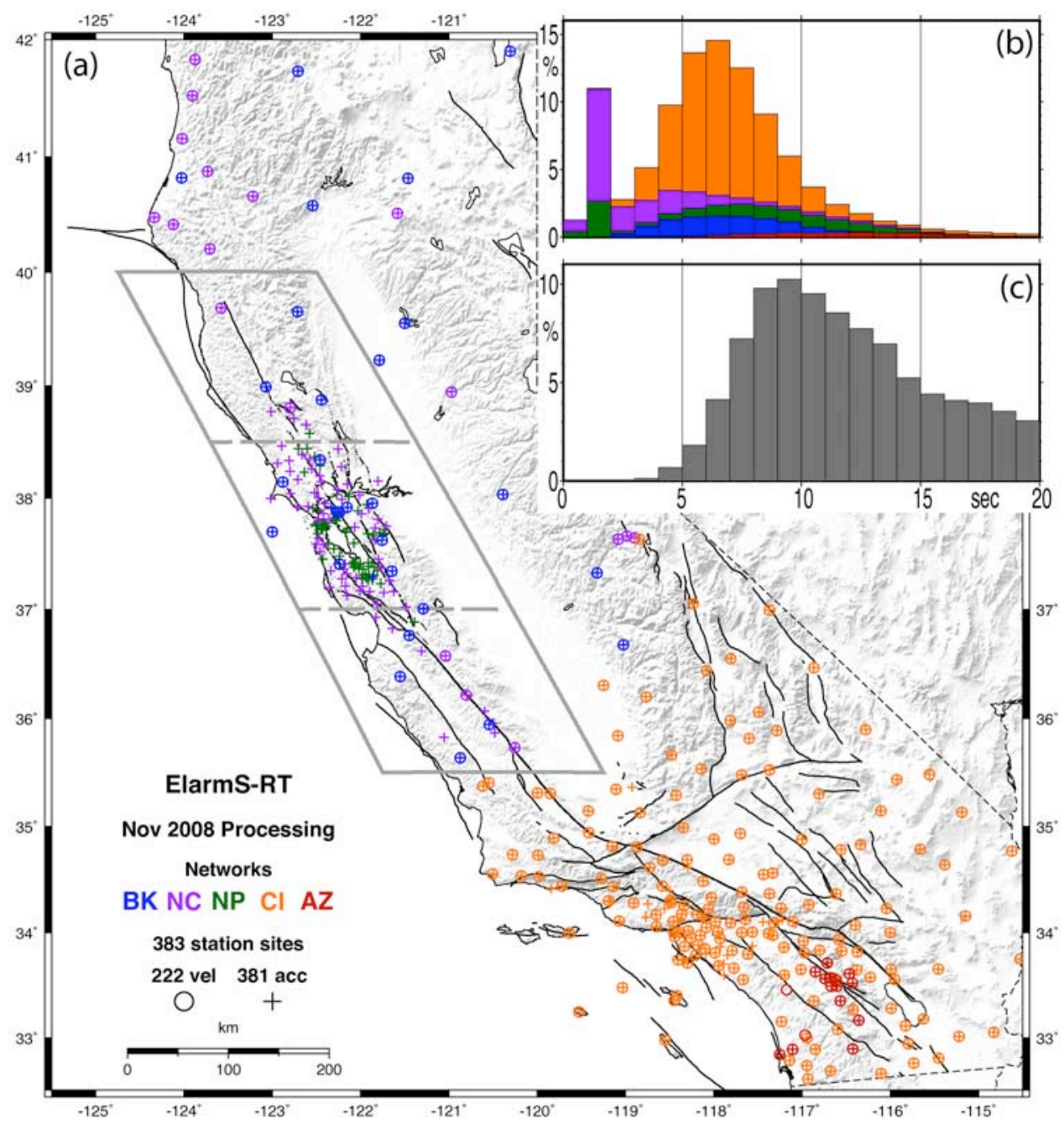

Figure 1. (a) Map of the stations currently integrated into the real-time implementation of ElarmS in California. A total of 383 station sites are equipped with a total of 222 broadband velocity instruments (circles) and 381 accelerometers (crosses). The stations are provided by the Berkeley Digital Seismic Network (BK - blue), the Northern California Network (NC purple) and the National Strong Motion Network (NP - green), the Southern California Seismic Network (CI - orange), and the Anza Network (AZ - red). The grey box is explained in the text. (b) Waveform telemetry latency for the seismic networks: the delay between the absolute time of waveform data and when it arrives in the first shared memory region at the network processing center, i.e., at the beginning of the ElarmS processing sequence. Most of this delay is due to data loggers waiting to fill a data packet before sending the data to the network center. (c) Total ElarmS latency: delay between the absolute time of a P-wave trigger and the time stamp of the EVM output file when that trigger has first been integrated into the ElarmS event detection and hazard assessment. This latency includes the waveform latency shown in Figure 1b plus all ElarmS processing and telemetry of WP data from network centers to EVM at Berkeley (see section 2).

[5] The ElarmS magnitude estimate is based on the amplitude and frequency content of the P-wave arrival. The vertical component of all stations is continuously converted into acceleration, velocity, displacement and predominant period using recursive relations [see Allen and Kanamori, 2003; Wu and Kanamori, 2005; Wurman et al., 2007]. Starting $0.5 \mathrm{sec}$ after a P-wave trigger, the maximum amplitude and predominant period is reported every $0.1 \mathrm{sec}$ for a total of $4 \mathrm{sec}$. For a given trigger from a velocity (or acceleration) instrument, the maximum observed displacement, $\mathrm{P}_{\mathrm{d}}$, (or velocity, $\mathrm{P}_{\mathrm{v}}$ ) and predominant period, $\tau_{p}^{\max }$, is converted to a magnitude estimate using empirical scaling relations [Tsang et al., 2007; Wurman et al., 2007]. When a higher value is observed later in the $4 \mathrm{sec}$ window the magnitude estimate from that station is revised. The positive correlations between magnitude and $\tau_{p}^{\max }, \mathrm{P}_{\mathrm{d}}$ or $\mathrm{P}_{\mathrm{v}}$ mean that any revision for a single station will be an increase in the magnitude estimate. Magnitude estimates for all triggered stations are averaged at each point in time to provide a single estimate for the event.

[6] The final step is to translate the location and magnitude estimate into peak ground shaking predictions for all locations, and to plot them on a map, the ElarmS-AlertMap. The USGS ShakeMap software [Wald et al., 2005] provides a framework to do this. Ground motion attenuation relations are used to predict the distribution of Peak Ground Velocity (PGV), Peak Ground Acceleration (PGA), and Instrumental Modified Mercalli Intensity (MMI) as a function of the 
location and magnitude with corrections for geology. As observations of PGV and PGA are made at individual stations they are also incorporated into the AlertMap. The initial AlertMap is therefore purely predictive as no PGA and PGV observations have been made. But with time, as PGV and PGA observations are made and incorporated by ElarmS, the AlertMap evolves into a typical ShakeMap, which is primarily a map of observations.

\section{Real-Time Implementation and Distribution}

[7] The ElarmS methodology was developed offline using earthquake records from California, the Pacific Northwest, Japan and Taiwan [Allen and Kanamori, 2003; Olson and Allen, 2005]. The process of porting the methodology to the real-time system of the California Integrated Seismic Network (CISN) began in 2006 as part of a statewide effort to test several early warning methodologies [see Bose et al., 2009; G. Cua et al., Real-time performance of the Virtual Seismologist method in southern California, submitted to Geophysical Research Letters, 2008]. The methodology naturally divides into a waveform processing module (WP) and an event monitoring module (EVM). WP operates on each data channel individually to reduce the seismic waveform to parameters including trigger times, $\mathrm{P}_{\mathrm{d}}, \mathrm{P}_{\mathrm{v}}, \tau_{p}^{\max }$, PGV, PGA and signal-to-noise levels. The WP module can therefore be distributed. It currently runs at UC Berkeley processing waveforms from the Berkeley Digital Seismic Network (network code BK), at the USGS Menlo Park processing the Northern California Seismic Network (NC) and some USGS Strong Motion Network (NP) data, and at Caltech/USGS Pasadena processing Southern California Seismic Network (CI), the Anza Network (AZ), and additional NP data. WP output parameters are telemetered to UC Berkeley where a single implementation of the EVM module integrates data from across the state to detect and analyze earthquake occurrence in real-time.

[8] Each second EVM outputs a list of all current earthquakes including their locations, estimated magnitudes, associated triggers and PGA and PGV observations. As this manuscript is being written, the translation of the EVM output into the graphical AlertMaps is not done in real-time, as the process takes more that $1 \mathrm{sec}$ per map frame. Instead, the AlertMaps are generated automatically in the minutes following events of interest, using only data from the realtime EVM output files.

[9] Testing of the real-time implementation of ElarmS in California started in October 2007 when WP and EVM were started at UC Berkeley processing data from 40 stations in northern California belonging to $\mathrm{BK}$ and NC. In April 2008 WP started at the USGS Menlo Park incorporating all stations from BK, NC and NP that could be used in northern California. In addition, 15 stations in southern California with direct telemetry to Berkeley were incorporated making a total of 180 stations. In November 2008 WP was initiated at Caltech/USGS Pasadena completing the state-wide coverage. Waveform data from 383 stations (222 velocity instruments and 381 accelerometers) of the BK, NC, NP, CI and AZ networks (Figure 1) are currently processed by WP at the three network centers. WP output parameters are telemetered to a single state-wide EVM at Berkeley. The real-time implementation of ElarmS is now processing all stations in California that can be used by the system.

\section{ElarmS Performance: Alum Rock Earthquake}

[10] The Alum Rock earthquake occurred October 31, 2007 at 03:04:54.8 UTC, 8:04 pm on October $30^{\text {th }}$ local time. The CISN magnitude estimates were $\mathrm{M}_{\mathrm{w}} 5.4$ and $M_{L}$ 5.6. The earthquake was on the Calaveras Fault in the southern SFBA, about $15 \mathrm{~km}$ northeast of San Jose (Figure 2e). It was the largest earthquake to have occurred in the region since the $1989 \mathrm{M}_{\mathrm{w}} 6.9$ Loma Prieta earthquake and was widely felt, toppling books and ornaments across the SFBA. At the time of the earthquake the real-time implementation of ElarmS had been operating for 20 days and included a total of 40 seismic stations from the BK and NC networks. The waveform data from these stations streamed into the WP algorithms at UC Berkeley, which reduced them to parametric data and passed them to EVM. At the time EVM was processing $15 \mathrm{sec}$ behind real-time.

[11] EVM first detected the earthquake at 03:05:14 when it processed the data for the 1-sec time window ending at 03:04:59 at which time stations $\mathrm{MHC}$ and SCCB triggered on the P-wave arrival (Figure 2a). One second later, at 03:05:15, a third station (WENL) triggered on the P-wave, improving the location (Figure $2 \mathrm{~b}$ and Table 1), and EVM made its first magnitude estimate of 5.2 using $\mathrm{P}_{\mathrm{d}}, \mathrm{P}_{\mathrm{v}}$ and $\tau_{p}^{\max }$ from the first two stations that triggered (MHC and $\mathrm{SCCB}$ ). When the location and magnitude are translated into PGA, PGV and MMI estimates, the error in MMI, obtained by comparing the predictions at all stations within $100 \mathrm{~km}$ to the observations, is $0.2 \pm 0.7$ (Table 1 ); compare the predicted AlertMap (Figure 2b) with the CISN ShakeMap (Figure 2e). The processing at 03:05:16 incorporated the first observation of peak ground shaking at the closest station, MHC, which lowered the predicted shaking intensity (Figure 2c) and made the average MMI error $-0.2 \pm$ 0.7 . The magnitude estimate also increased to 5.8. At 03:05:17 a fourth station triggered (JRSC), the magnitude estimate increased slightly to 5.9 and the predicted MMI error returned to $0.2 \pm 0.7$ (Figure $2 \mathrm{~d}$ ). From this time on the magnitude estimate had little effect on the error in ground motion as the PGA and PGV observations dominated the ground motion predictions. Data continued to stream into the system and the event assessment was updated but little changed after this time.

[12] The three largest cities in the SFBA are San Jose, Oakland and San Francisco (Figure 2). The S-wave arrival, and the onset of peak ground shaking, observed at seismometers in these cities during the event occurred at 03:05:01 in San Jose, 03:05:15 in Oakland and 03:05:18 in San Francisco. Figure $2 \mathrm{f}$ shows the seismogram recorded at JPR in San Francisco along with a timeline showing when the EVM output described above was available. The ElarmS computers accurately detected and assessed the earthquake hazard before the beginning of peak shaking in San Francisco.

\section{ElarmS Performance: Chino Hills Earthquake}

[13] The $M_{w} 5.4$ Chino Hills earthquake occurred in the LAMA region on July 29, 2008. At the time ElarmS was 

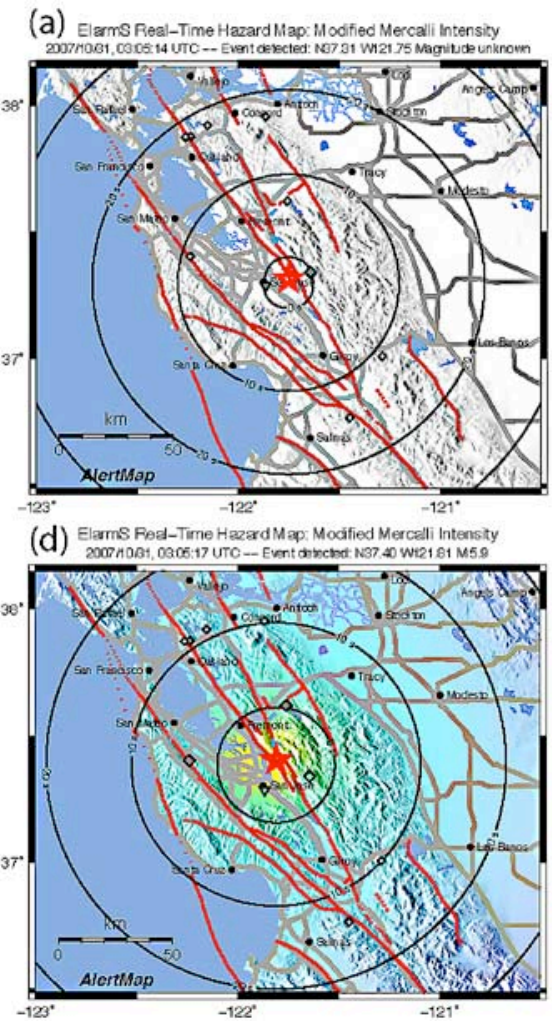

(b) ElarmS Rial-Time Hezard Map: Modified Mercalli Intensity

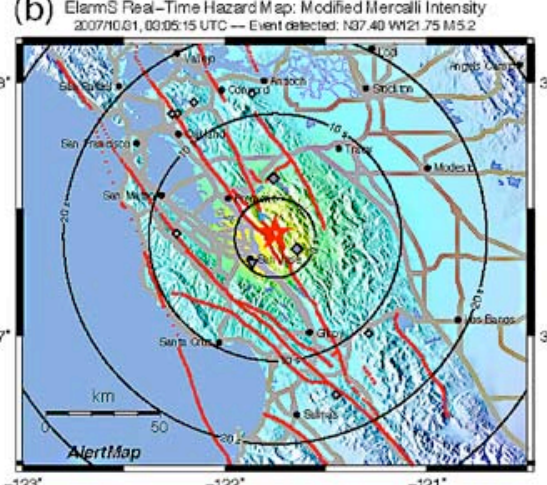

(e)

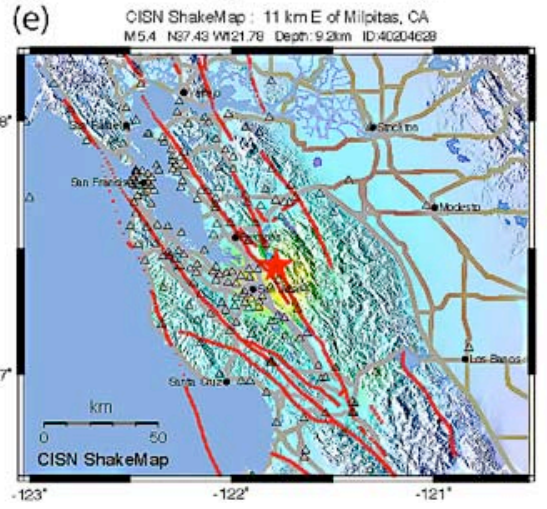

(C) Elams Rea-Time Hazard Map: Modified Mercalli intensity
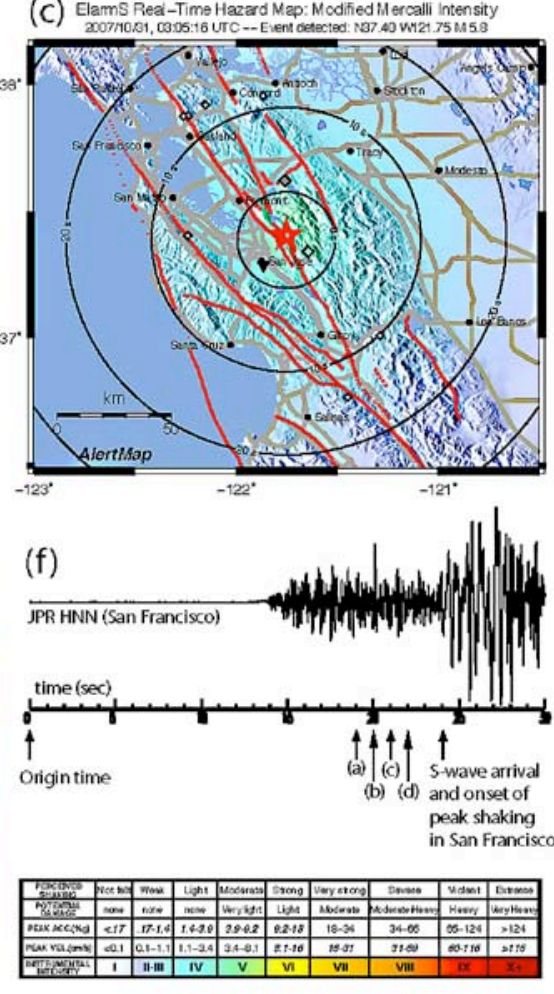

Figure 2. ElarmS real-time processing output for the 03:04:55 October 31, 2007 (UTC), $\mathrm{M}_{\mathrm{w}} 5.4$ earthquake in the southern SFBA. (a-d) AlertMaps generated from the EVM output at 03:05:14, 15, 16 and 17. The background color scale shows the predicted MMI at each point in time using the usual ShakeMap color scale (shown lower right). Seismic stations are normally white, grey when they have detected a P-wave trigger, black during the period of expected peak ground shaking, and colored according to the MMI scale once peak shaking has been observed. The star shows the earthquake location and the circles are the estimated warning time. Solid blue regions are ocean, faults are red and major roads are grey. (e) CISN ShakeMap for the event for comparison. (f) Seismic waveform from the north component of station JPN located in San Francisco. The time-line shows the time at which the EVM output for the four frames in Figures $2 \mathrm{a}-2 \mathrm{~d}$ were generated with respect to the shaking in San Francisco. The predictions were made before the S-wave arrival and period of peak shaking in the city.

processing $\sim 180$ stations but only 15 from southern California. Transfer of the WP parameter data to EVM was also delayed by $\sim 24$ sec due to a technical problem. However, the processing of this event provides useful information about the accuracy of ElarmS information when there is a sparse station distribution; only 3 stations are within $100 \mathrm{~km}$. When the first station triggers the magnitude estimate is 5.4 but the location is poor (located at the first station to trigger), located $36 \mathrm{~km}$ from the epicenter. With the second station trigger, $3 \mathrm{sec}$ later, the magnitude estimate becomes 5.8 and

Table 1. ElarmS Estimates for the Alum Rock Earthquake and Times at Which They Were Available on the ElarmS Computers at UC Berkeley $^{\mathrm{a}}$

\begin{tabular}{|c|c|c|c|c|c|c|c|c|c|}
\hline $\begin{array}{c}\text { Time } \\
\text { of } \\
\text { Estimate } \\
\end{array}$ & $\begin{array}{c}\text { Time } \\
\text { After } \\
\text { Earthquake } \\
\text { Origin } \\
\end{array}$ & $\begin{array}{l}\text { Number } \\
\text { of } \\
\text { Station } \\
\text { Triggers } \\
\end{array}$ & Latitude & Longitude & $\begin{array}{c}\text { Location } \\
\text { Error } \\
(\mathrm{km}) \\
\end{array}$ & $\begin{array}{c}\text { ElarmS } \\
\text { Magnitude }\end{array}$ & $\begin{array}{c}\text { Predicted } \\
\text { MMI } \\
\text { Error } \\
\end{array}$ & $\begin{array}{c}\text { Predicted } \\
\text { PGA } \\
\text { Error } \\
\end{array}$ & $\begin{array}{c}\text { Predicted } \\
\text { PGV } \\
\text { Error } \\
\end{array}$ \\
\hline $03: 05: 14$ & $19 \mathrm{sec}$ & 2 & 37.3150 & -121.751 & 13.0 & & & & \\
\hline $03: 05: 15$ & $20 \mathrm{sec}$ & 3 & 37.4049 & -121.751 & 3.8 & 5.2 & $0.2 \pm 0.7$ & $0.3 \pm 0.5$ & $0.2 \pm 0.4$ \\
\hline $03: 05: 16$ & $21 \mathrm{sec}$ & 3 & 37.4049 & -121.751 & 3.8 & 5.8 & $-0.2 \pm 0.7$ & $0.1 \pm 0.5$ & $0.2 \pm 0.4$ \\
\hline $03: 05: 17$ & $22 \mathrm{sec}$ & 4 & 37.4049 & -121.808 & 3.7 & 5.9 & $0.2 \pm 0.8$ & $0.4 \pm 0.5$ & $0.4 \pm 0.5$ \\
\hline $03: 05: 18$ & $23 \mathrm{sec}$ & 4 & 37.4049 & -121.808 & 3.7 & 6.0 & $0.2 \pm 0.8$ & $0.4 \pm 0.5$ & $0.4 \pm 0.5$ \\
\hline 03:05:19 & $24 \mathrm{sec}$ & 4 & 37.4049 & -121.808 & 3.7 & 6.0 & $0.2 \pm 0.8$ & $0.4 \pm 0.5$ & $0.4 \pm 0.5$ \\
\hline 03:05:20 & $25 \mathrm{sec}$ & 4 & 37.4049 & -121.808 & 3.7 & 6.0 & $0.1 \pm 0.8$ & $0.3 \pm 0.5$ & $0.1 \pm 0.5$ \\
\hline
\end{tabular}

${ }^{a}$ The MMI, PGA and PGV error columns show the average and standard deviation of the difference between the ElarmS prediction and the observation at stations within $100 \mathrm{~km}$ that had not yet observed peak shaking. For PGA and PGV the difference between the logarithms is used. The event parameters estimated by the CISN are: 03:05:55 on October 31, 2007 (UTC), $\mathrm{M}_{\mathrm{w}} 5.4, \mathrm{M}_{\mathrm{L}} 5.6,37.430^{\circ} \mathrm{N}$ and $121.780^{\circ} \mathrm{W}$. 
the location error drops to $12 \mathrm{~km}$. When the third station triggers $6 \mathrm{sec}$ later the magnitude estimate becomes 5.5 and the location error is $6 \mathrm{~km}$.

\section{Network Latencies}

[14] Every second required to telemeter data is a second reduction in warning time. Minimizing the time needed for data telemetry and processing is therefore an important aspect of a network-based early warning system. Figure 1 shows the current data latencies for ElarmS in California. The first cause of latency is the delay in getting data to the first shared memory region at its network processing site at UC Berkeley, Caltech/USGS Pasadena or USGS Menlo Park (Figure 1b). Most of this delay is due to packetization of data. Data loggers at each station wait until a data packet is full before sending it across the telemetry system. The smallest latencies are of $1-2 \mathrm{sec}$ from data loggers used at some sites by NC and NP. They fill 1-sec packets before sending the data. More commonly, data loggers fill packets of a fixed, but configurable, byte size before sending the data. Depending on the compression rate these packets currently range from 4-6 sec of data. Modifications to the configuration of many could reduce the size of these packets reducing the overall latency. The actual telemetry (communication) delay at most sites most of the time is a fraction of a second, though packets can be delayed resulting in the long tail to the distribution. The median waveform data latencies are 2.0, 6.5, 6.6, 6.6 and $11.5 \mathrm{sec}$ for $\mathrm{NC}, \mathrm{CI}, \mathrm{BK}$, $\mathrm{NP}$ and $\mathrm{AZ}$ respectively. AZ has apparently longer latencies because AZ data is forwarded from Scripps to Caltech before it is processed by ElarmS. The median latency over all station channels is $6.5 \mathrm{sec}$.

[15] Once the waveform data has arrived at the first shared memory region at a network center, WP processes the data to determine parameters. Parameters from Caltech/ USGS Pasadena and USGS Menlo Park are then forwarded to UC Berkeley where they are incorporated into EVM as they arrive. Figure 1c shows the total latency in incorporating P-wave trigger times into the EVM output representing the current latency of the entire system. The median delay is $11.8 \mathrm{sec}$ and the distribution has a positive-skew meaning that most frequent latency is in the $9-10 \mathrm{sec}$ window but there is a long tail at higher latencies. The actual processing of data by WP and EVM each takes a fraction of a second. Most of this additional latency is therefore due to the process of moving data between the four shared memory regions at the various stages of processing (including between network centers).

\section{Discussion, Conclusion, and Outlook}

[16] The two example earthquakes described above illustrate the real-time performance of ElarmS to date. This performance mirrors the automated offline ElarmS processing that has been underway in northern California since February 2006 [Wurman et al., 2007]. The grey box in Figure 1 delineates the region in northern California where ElarmS is able to detect earthquakes and assess hazard accurately. Outside the box and in northern California the station spacing is insufficient to locate events using the first few stations to trigger.
[17] The box in Figure 1 is subdivided by dashed grey lines separating the SFBA, where station density is greatest, from neighboring areas along the San Andreas Fault System. In this region ElarmS performance has been excellent as illustrated by the Alum Rock example. The system detects, locates and provides good ground shaking estimates within a few seconds. While Elarms still detects, locates and generates good ground motion predictions in the regions to the north and south of the SFBA where the station density is lower, the delay is greater as it takes longer for P-waves to be detected by several stations. The performance in these two sub-regions of the grey box is similar to that for the Chino Hills earthquake described above which was detected by the real-time system while only 15 stations were being used in southern California.

[18] The high station-density SFBA region in Figure 1 is characterized by a station spacing of $<20 \mathrm{~km}$; the lowerdensity regions inside the grey box (Figure 1) to the north and south of the SFBA have stations spacing of $20-100 \mathrm{~km}$. Outside the grey box (and in northern California) the spacing is $>100 \mathrm{~km}$ and the azimuthal coverage is poor. We have no assessment yet for southern California but expect similar behavior. We conclude that a two-dimensional grid of stations with a spacing of $\sim 20 \mathrm{~km}$ or less is appropriate to provide early warning using ElarmS. A statewide early warning system will therefore benefit from densification of stations in earthquake source regions where the station coverage is currently greater than $\sim 20 \mathrm{~km}$.

[19] The state-wide real-time test of ElarmS has only just begun (November 2008) so there will undoubtedly be additional methodology development necessary to handle the myriad of technical issues that arise as a result of processing the $\sim 15$ billion observations per day that arrive with varying data latencies and various seismological and electronic sources of noise. In addition, further development is necessary to enhance system performance for large $(M>$ 6.5) earthquakes and the warning latency needs to be reduced and minimized which can be done by improving the codes (currently $5 \mathrm{sec}$ delay) and upgrading station hardware (currently $6.5 \mathrm{sec}$ delay).

[20] Finally, now that the test early-warning system is operational and providing event information, it is time to start working with a small group of users in order to develop both the technical and sociological aspects of providing rapid real-time earthquake information. A variety of communication systems are available to provide warnings including the internet, wireless devices, cellphones, and public and private dedicated systems. This will perhaps be the greatest challenge for the seismology community: effectively communicating earthquake hazard information to the public so that it can be and is used to mitigate the impacts of future events in seconds.

[21] Acknowledgments. The real-time implementation and testing of ElarmS in California is part of a project by the California Integrated Seismic Network (CISN.org) to test several early warning methodologies in the state. In addition to the co-authors of this manuscript, the real-time testing of ElarmS has only been possible thanks to the contributions of M. Bose, E. Hauksson, T. Heaton and K. Solanki at Caltech; T. Jordan and P. Maechling at USC and SCEC; D. Given and D. Oppenheimer at the USGS; M. Zeleznik of Saya Systems; and G. Cua at the Swiss Seismological Service. The project is funded by the USGS through cooperative agreement 06HQAG0147. We also thank Yih-Min Wu and an anonymous reviewer for helpful comments. 


\section{References}

Allen, R. (1978), Automatic earthquake recognition and timing from single traces, Bull. Seismol. Soc. Am., 68, 1521-1532.

Allen, R. M., and H. Kanamori (2003), The potential for earthquake early warning in southern California, Science, 300, 786-789.

Bose, M., E. Hauksson, K. Solanki, H. Kanamori, and T. H. Heaton (2009), Real-time testing of the on-site warning algorithm in southern California and its performance during the July 292008 Mw5.4 Chino Hills earthquake, Geophys. Res. Lett., 36, L00B03, doi:10.1029/2008GL036366.

Espinosa Aranda, J. M., A. Jimenez, G. Ibarrola, F. Alcantar, A. Aguilar, M. Inostroza, and S. Maldonado (1995), Mexico City seismic alert system, Seismol. Res. Lett., 66, 42-52.

Gasparini, P., G. Manfredi, and J. Zschau (2007), Earthquake Early Warning Systems, 350 pp., Springer, Berlin.

Hoshiba, M., O. Kamigaichi, M. Saito, S. Tsukada, and N. Hamada (2008) Earthquake early warning starts nationwide in Japan, Eos Trans. $A G U$, 89(8), doi:10.1029/2008EO080001.

Hsiao, N.-C., Y.-M. Wu, T.-C. Shin, L. Zhao, and T.-L. Teng (2009), Development of earthquake early warning system in Taiwan, Geophys. Res. Lett., 36, L00B02, doi:10.1029/2008GL036596.

Lockman, A., and R. M. Allen (2005), Single station earthquake characterization for early warning, Bull. Seismol. Soc. Am., 95, 2029-2039.

Olson, E., and R. M. Allen (2005), The deterministic nature of earthquake rupture, Nature, $438,212-215$.
Tsang, L. L. H., R. M. Allen, and G. Wurman (2007), Magnitude scaling relations from P-waves in southern California, Geophys. Res. Lett., 34 L19304, doi:10.1029/2007GL031077.

Wald, D. J., C. B. Worden, V. Quitoriano, and K. L. Pankow (2005), ShakeMap manual: Technical manual, user's guide, and software guide, U.S. Geol. Surv. Tech. Methods, 12-A1.

Wu, Y. M., and H. Kanamori (2005), Rapid assessment of damage potential of earthquakes in Taiwan from the beginning of P waves, Bull. Seismol. Soc. Am., 95, 1181-1185.

Wu, Y.-M., and H. Kanamori (2008a), Development of an earthquake early warning system using real-time strong motion signals, Sensors, 8, 1-9.

Wu, Y.-M., and H. Kanamori (2008b), Exploring the feasibility of on-site earthquake early warning using close-in records of the 2007 Noto Hanto earthquake, Earth Planets Space, 60, 155-160.

Wurman, G., R. M. Allen, and P. Lombard (2007), Toward earthquake early warning in northern California, J. Geophys. Res., 112, B08311, doi:10.1029/2006JB004830.

R. M. Allen, H. Brown, M. Hellweg, O. Khainovski, P. Lombard and D. Neuhauser, Seismological Laboratory, University of California, 215 McCone Hall, Berkeley, CA 94720-4760, USA. (rallen@berkeley. edu) 